\title{
Cloud particle size distributions measured with an airborne digital in-line holographic instrument
}

\author{
J. P. Fugal ${ }^{1, *}$ and R. A. Shaw ${ }^{1}$ \\ ${ }^{1}$ Department of Physics, Michigan Technological University, Houghton, MI 49931, USA \\ *now at: National Center for Atmospheric Research, P.O. Box 3000, Boulder, CO 80307, USA
}

Received: 7 February 2009 - Published in Atmos. Meas. Tech. Discuss.: 3 March 2009

Revised: 28 May 2009 - Accepted: 29 May 2009 - Published: 17 June 2009

\begin{abstract}
Holographic data from the prototype airborne digital holographic instrument HOLODEC (Holographic Detector for Clouds), taken during test flights are digitally reconstructed to obtain the size (equivalent diameters in the range 23 to $1000 \mu \mathrm{m}$ ), three-dimensional position, and twodimensional image of ice particles and then ice particle size distributions and number densities are calculated using an automated algorithm with minimal user intervention. The holographic method offers the advantages of a well-defined sample volume size that is not dependent on particle size or airspeed, and offers a unique method of detecting shattered particles. The holographic method also allows the volume sample rate to be increased beyond that of the prototype HOLODEC instrument, limited solely by camera technology.

HOLODEC size distributions taken in mixed-phase regions of cloud compare well to size distributions from a PMS FSSP probe also onboard the aircraft during the test flights. A conservative algorithm for detecting shattered particles utilizing their depth-position along the optical axis eliminates the obvious ice particle shattering events from the data set. In this particular case, the size distributions of non-shattered particles are reduced by approximately a factor of two for particles 15 to $70 \mu \mathrm{m}$ in equivalent diameter, compared to size distributions of all particles.
\end{abstract}

\section{Introduction}

Accurate ice particle size distributions and number densities are necessary for understanding and modeling cloud processes such as precipitation formation and radiative transfer, and for validation of remote sensing and satellite measurements. Many methods and instruments have been devised

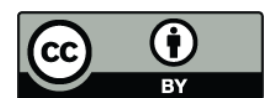

Correspondence to: J. P. Fugal

(fugal@ucar.edu) to measure ice particles, yet there is still considerable uncertainty in measuring small $(\lesssim 150 \mu \mathrm{m})$ ice particles (Baum et al., 2005b; McFarquhar et al., 2007). Beyond the inherent uncertainty in counting statistics, the uncertainty in small-ice size distributions results primarily from poorly defined sample volumes, instrument resolution limits, and instrumentinduced ice particle breakup. Digital holography is one of several approaches that allows for improvements in the measurement of ice size distributions. In this paper, we present results from the Holographic Detector for Clouds (HOLODEC), which is a prototype airborne digital holographic instrument. In relation to the existing uncertainties, holography has the benefit of providing a well-defined sample volume, a uniform and well-defined resolution, and threedimensional spatial information that can assist in identifying shards of shattered crystals. The difficulty of using digital holography is the added complexity in data processing, which includes digital reconstruction and particle detection and characterization. Details of the method and algorithms we use to automate the processing of holograms taken during the test flights of HOLODEC are presented in Fugal et al. (2009) and are only summarized here.

The holographic method is not new to atmospheric science and, in fact, some of the earliest applications of optical holography were to measure atmospheric particles (e.g. Thompson, 1974; Trolinger, 1975). Subsequently, analog holography (i.e. recording with photographic emulsions) was applied by various groups, including in an airborne setting (Kozikowska et al., 1984; Brown, 1989). More recent holographic instruments for atmospheric particle studies include the large-sample-volume HODAR (Borrmann and Jaenicke, 1993) which uses photographic plates, a prototype digital holographic instrument (Lawson and Cormack, 1995), and a new ground-based instrument utilizing two digital cameras in a cross-beam configuration (Raupach et al., 2006). A challenge that remains, however, is to take holography to the point where large numbers of ice crystals can

Published by Copernicus Publications on behalf of the European Geosciences Union. 
be reconstructed and ice size distributions determined in an automated fashion suitable for operational field use.

The HOLODEC instrument measures the shape (twodimensional shadowgraph), size, and three-dimensional (3D) position of every cloud particle coincident in its sample volume via digital in-line holography. It has the advantage of a sample volume that is not particle-size dependent (given an appropriate reconstruction method (Fugal et al., 2009)), nor air-speed dependent. It also has a unique ability to detect probable crystal-shattering events utilizing 3-D positions of cloud particles and the fact that shattered particles tend to appear as highly localized clusters in certain parts of the sample volume. The HOLODEC instrument flew aboard the NCAR C-130 aircraft in the IDEAS 3 project. The instrument itself, the basic reconstruction method, and examples of reconstructed particles were described by Fugal et al. (2004). It was shown that an airborne digital in-line holographic instrument could successfully measure cloud particles, both liquid water and ice, in the size range of approximately $25 \mu \mathrm{m}$ to $1 \mathrm{~mm}$, but only for a small number of particles for purposes of demonstration. Since then we have developed automated routines that can determine particle size and location in a broad range of sizes (Fugal et al., 2009), and in this paper we apply those routines to large sections of our data set to illustrate and evaluate the ability to measure size distributions, perform particle shattering corrections, etc.

To provide a context for the measurements we briefly describe some of the limitations of commonly used optical particle detectors for measuring ice crystal size distributions. First, there is a particle-size-dependent depth of focus and sensitivity for small particles in optical array probes such as the PMS 2D-C (Strapp et al., 2001; Korolev et al., 1998a; Baumgardner and Korolev, 1997). Second, light-scattering instruments, e.g. the Forward Scattering Spectrometer Probe (FSSP), are calibrated only for spherical particles (not ice particles). Third, some instruments, such as the Cloud Particle Imager (CPI), yield uncertain ice particle size distributions (Baum et al., 2005a) because air stream distortion and triggering mechanisms make it difficult to estimate the effective sample volume. Fourth, nearly all probes suffer in some degree from ice particles shattering on the leading parts of the instrument housing. When the shards are swept into the sample volume, the result is an over counting of small particles and an under counting of large particles (Field et al., 2006, 2003b; Korolev and Isaac, 2005; Gayet et al., 1996; Gardiner and Hallett, 1985; McFarquhar et al., 2007). Other errors resulting from air stream distortion caused by the aircraft, and imperfect calibration have also been discussed in the literature (Nagel et al., 2007; Korolev, 2007; Twohy and Rogers, 1993).

Remedies for some of these problems exist: for example, given certain assumptions FSSP size measurements can be approximately corrected for ice, effective instrument resolution can be improved via post-processing (Korolev, 2007), and instrument housings can be modified to reduce shattering
(Field et al., 2003b). Furthermore, new instruments are being developed to measure small ice particles without some of these problems, such as the Small Ice Detector (SID) (Field et al., 2003a) and the SPEC 2D-S (Stereo) probe (Lawson et al., 2006). The SID probe measures light scattered by ice particles at many angles, and can yield particle phase and size in the diameter range of approximately 1 to $50 \mu \mathrm{m}$. The SPEC 2D-S (Stereo) optical array probe can measure cloud particle sizes and two-dimensional profiles in the size range of about 10 to $1000 \mu \mathrm{m}$.

In this paper we analyze holograms of ice particles to show that digital inline holography and hologram processing algorithms can measure ice particle size distributions after rejecting shattered ice particles, and that the results are comparable to standard aircraft probes under certain conditions. This data processing is accomplished with minimal user intervention, and therefore is suitable for field measurements. In Sect. 2 we briefly summarize the automated hologram reconstruction, particle-finding and particle-sizing algorithms, and discuss the sampling characteristics of the HOLODEC probe relevant to measuring ice. In Sect. 3 we discuss the conditions under which we took the ice holograms and we present the results in Sect. 4. In Sect. 5, we discuss implications of our results and in Sect. 6, we summarize.

\section{Holographic reconstruction method and instrument parameters}

In this section, we briefly describe how we reconstruct holograms, detect particles, and determine their threedimensional location, two-dimensional profile and size. We also explain the particle-size detection limits of HOLODEC and their causes, as well as limits on its ability to measure ice particle size distributions and number densities.

\subsection{Hologram reconstruction and particle finding method}

Holograms from the data sets presented in this paper are reconstructed using the method described by Fugal et al. (2009) and so we only summarize it here. As a preliminary, we review the instrument parameters described in more detail by Fugal et al. (2004). The holograms are taken with a $527 \mathrm{~nm}$ wavelength, pulsed laser, and a $1024 \times 768,4.65 \mu \mathrm{m}$ pixel, 8 bit grayscale camera with particles confined by the windows in the probe arms to approximately 30 to $80 \mathrm{~mm}$ from the imaging chip of the camera. The laser pulse width of $20 \mathrm{~ns}$ and flight speed of about $100 \mathrm{~m} \mathrm{~s}^{-1}$ limits the particle motion in the hologram to about $2 \mu \mathrm{m}$ or less than half a pixel width.

In preprocessing, each hologram is divided by a background image made by taking the median of seven of its neighboring holograms in time with no other filtering or noise removal processing. We do, however, take the contrast negative of the image so the ice particles appear as bright 
shapes on a darker background. Each hologram is then reconstructed using the Huygens-Fresnel filtering method in combination with a low-pass filter that enforces a uniform resolution limit throughout the sample volume (Fugal et al., 2009). The position of each particle along the optical axis is then found using the edge sharpness algorithm detailed by Fugal et al. (2009), and at that axial position, the centroid in the other two dimensions is calculated as well as an equivalent area diameter. Using simulated holograms, we have found that the edge sharpness algorithm is robust in finding the particle's axial position over a range of particle sizes extending from $25 \mu \mathrm{m}$ to $1 \mathrm{~mm}$ (Fugal et al., 2009). Because of the noise of edge effects inherent in hologram reconstruction, we eliminate from the total data set any particle in the outer $5 \%$ of each edge of the hologram. As a result the sample volume of each hologram is reduced to $0.9^{2}=81 \%$ of the possible sample volume.

\subsection{Detection of particle shattering}

We detect ice particle shattering by taking advantage of HOLODEC's ability to measure the depth-position or position along the optical axis of each particle in the sample volume. This is useful as shards of shattered particles tend to stream along an aerodynamic surface into the sample volume and appear as highly localized clusters along the optical axis. Figure 1 shows a hologram reconstructed at a plane (perpendicular to the optical axis; airflow is top to bottom) where a disproportionate number of ice particles appear in or nearly in focus as can be seen in the histogram of the location of ice particles along the optical axis. Note the high concentration of particles around $66.5 \mathrm{~mm}$ which is the distance at which the hologram is reconstructed. To detect holograms containing shattered ice crystals, we search for high concentrations of particles along the optical axis. Specifically, for the data presented here we use a threshold of 10 particles detected within $5 \mathrm{~mm}$ depth, which is equivalent to a local concentration of $\sim 100$ ice particles $\mathrm{cm}^{3}$. This is a conservative threshold considering that the average density is about 3 particles per hologram $\left(\sim 10\right.$ particles $\left.\mathrm{cm}^{3}\right)$ in the size range considered and recognizing there is little likelihood of such large natural concentration fluctuations. There are possibly more optimal (and necessarily more complex) methods to detect shattering, but in this paper we have chosen a simple method with a conservative threshold to detect and remove only the most obvious shattering events. In fact, only $3 \%$ of the holograms (or sample volumes) in the entire data set are marked as shattered, but they contain $37 \%$ all of the particles in the data set.

Figure 2 shows an example of an ice particle in the process of breaking up, likely due to impact with the instrument housing or to shear in the airflow around the window housing. Again, the localized cluster of particles allows them to be identified as resulting from a shattering event. Figure 3 shows the effectiveness of this simple shattering detection
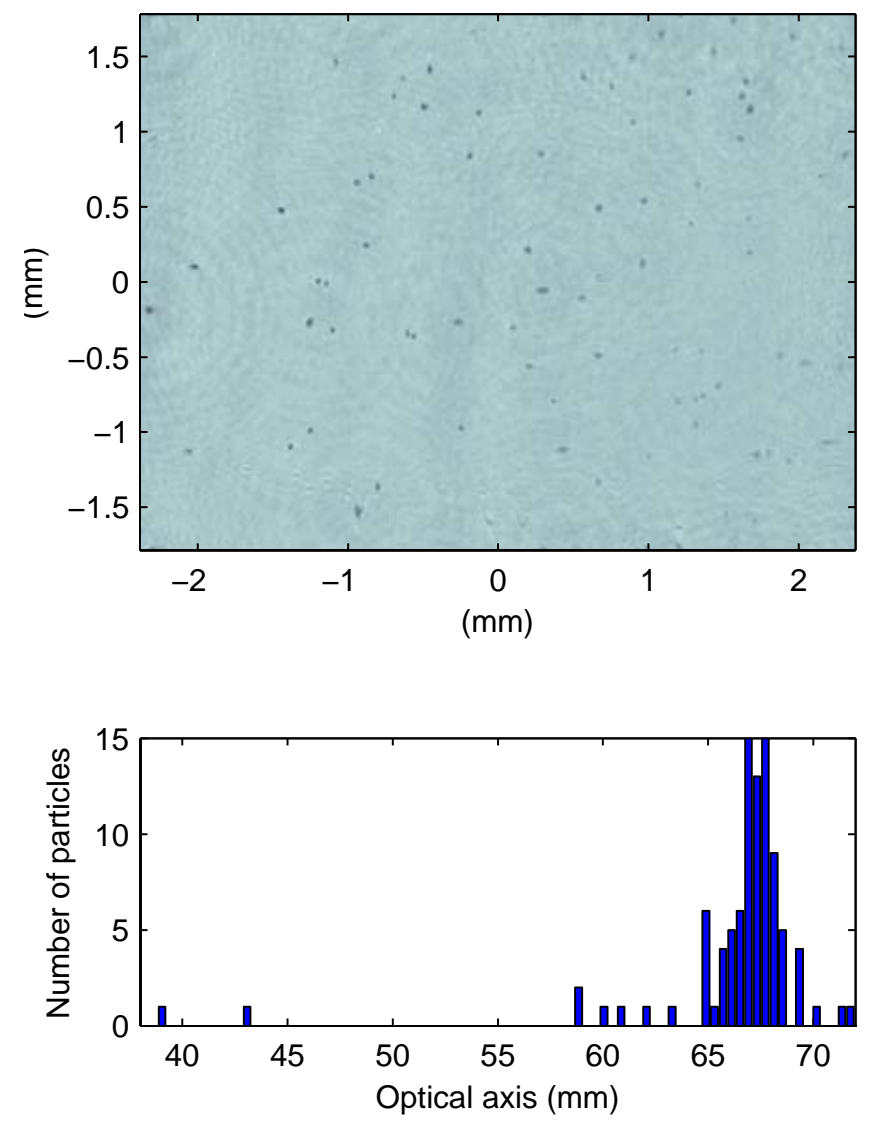

Fig. 1. The top panel shows a hologram from Research Flight 200309-17 reconstructed to $66.5 \mathrm{~mm}$. The reconstructed image has many particles in focus at one depth and many others nearly in focus. The bottom panel is a histogram of the z-positions of all particles in the sample volume. This is suggestive of shards of a single impacted crystal tracing an aerodynamic surface about the instrument housing.

scheme. The top panel shows a histogram of the position of all particles along the optical axis and the lower panel excludes particles in holograms flagged as containing shattered particles. Note that most of the excluded shattered ice particles appear nearer the windows or the edges of the sample volume. The non-uniform distribution of these shattered particles appearing near the windows is consistent with particles shattered on or near the tips of the instrument arms, and that are then swept into the near-arm part of the sample volume. Further, the bottom panel shows a nearly uniform detection rate for particles of all sizes across the optical axis after rejecting shattered ice particles, as we expect to see for a nearly uniform random distribution of particles in cloud. The attainment of a uniform distribution when shattering artifacts are removed suggests that the observed concentration nonuniformities are not a result of other effects such as flow distortion. It also provides support for the assumption that the observed breakup events are instrument induced, rather than naturally occurring (presumably, naturally occurring breakup 


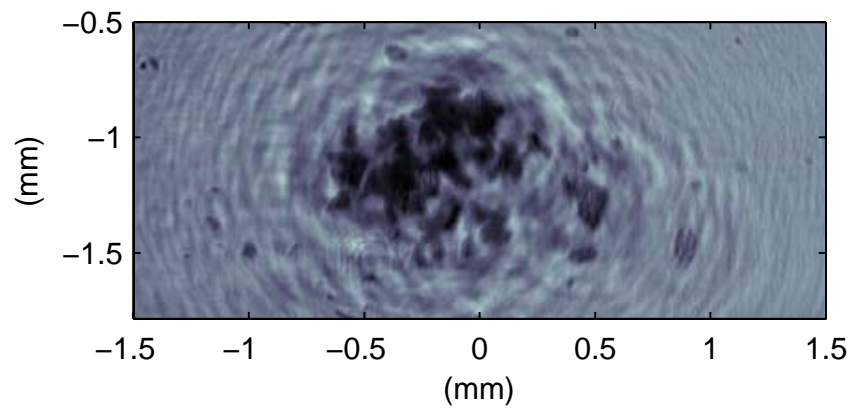

Fig. 2. An ice particle in the process of shattering about $10 \mathrm{~mm}$ from one of HOLODEC's windows.

processes would be observed uniformly over the measurement volume).

\subsection{Instrument parameters}

We now explain what determines HOLODEC's sampling characteristics, including sample volume, volume sample rate, and detectable particle size range. The sample volume is determined by the camera CCD area that is not affected by noise from edge effects or particle images overlapping the edge of the hologram, and the space between the windows of the probe housing that is not severely affected by airstream distortion or the boundary layer around the instrument housing. For HOLODEC this valid sample volume is about $4.3 \times 3.6 \times 25 \mathrm{~mm}^{3}$ or about $0.4 \mathrm{~cm}^{3}$. In estimating the sample volume, we have applied no correction for the distortion of the airstream from the upstream probe parts. Simulations of the flow (using Fluent software) based on a simplified probe body indicate that the sample volume is compressed along the optical axis, and stretched in the other two dimensions. The compression and stretching do not completely cancel each other out, but the effect is on the order of $10 \%$ of the sample volume size.

The sample volume size is not a function of particle size because we use a low-pass filter as described by Fugal et al. (2009), which enforces a uniform minimum detectable particle size throughout the sample volume. Effectively it makes particles of the same size and shape appear the same in reconstructed images independent of the reconstructed distance. This is done at the expense of overlooking some smaller particles that would be visible nearer the camera, but not at the far end of the sample volume. While it is theoretically possible that we could define a variable sample volume as a function of particle size, given the noise in the holograms and the variety of particle sizes, shapes and orientations encountered, this would be exceedingly difficult and not likely very accurate. This is discussed in more detail by Fugal et al. (2009), who also discuss the detectability of particle of various sizes appearing in front of and/or near each other.

HOLODEC's volume sample rate is not dependent on air speed, but on the sample volume size and the frame rate
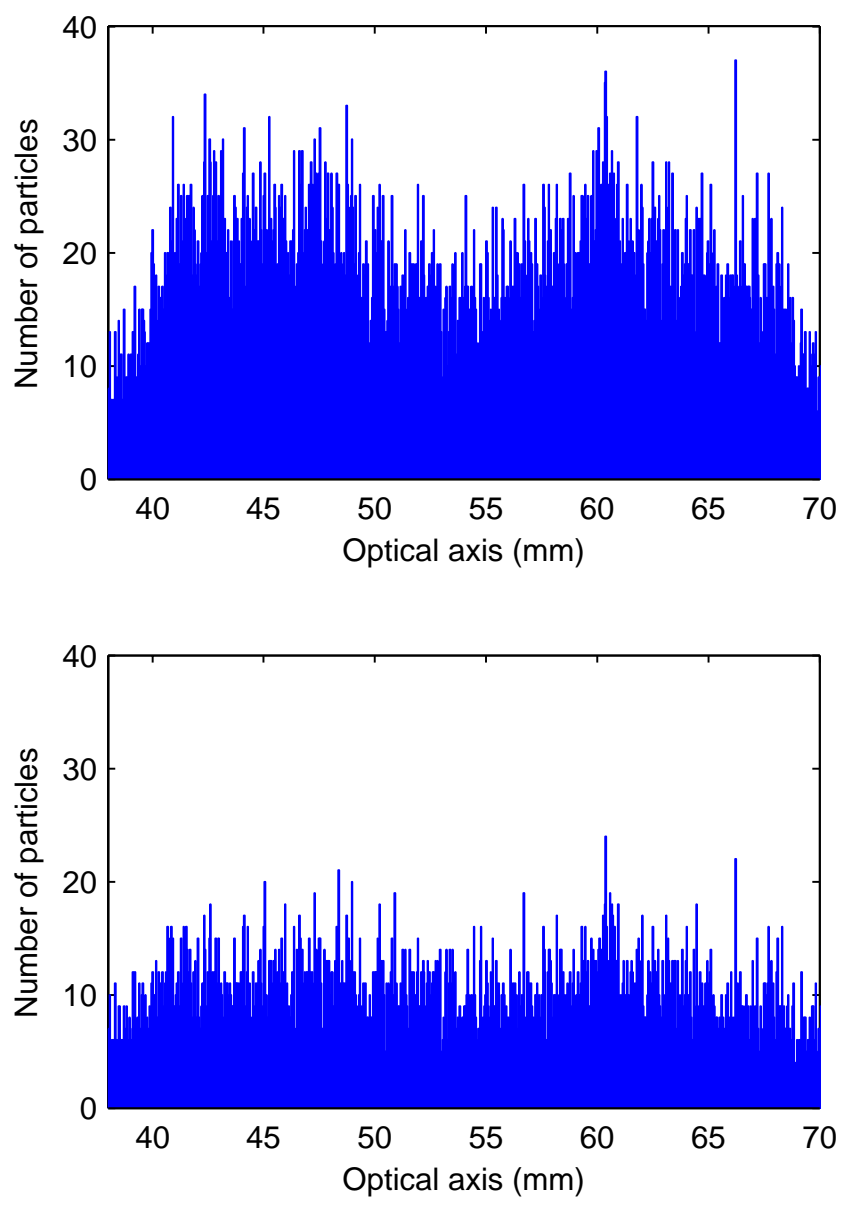

Fig. 3. In the top and bottom panels are histograms of optical-axis positions of particles from Research Flight 2003-09-17. The top panel shows all particles and the bottom panel excludes particles in holograms containing shattered particles. Note that rejecting shattered particles yields a more uniform distribution of particles along the optical axis.

of the camera. (The latter is true for camera frame rates low enough that sample volumes do not overlap, a limit that is technologically feasible now with commercially available high speed cameras and typical airspeeds.) For a $100 \mathrm{~m} \mathrm{~s}^{-1}$ flight speed, HOLODEC records one sample volume every $7 \mathrm{~m}$ and its sample rate is about $5 \mathrm{~cm}^{3} \mathrm{~s}^{-1}$. For comparison, the FSSP sample rate is around $30 \mathrm{~cm}^{3} \mathrm{~s}^{-1}$.

The minimum particle detection size is approximately $23 \mu \mathrm{m}$ or about 5 pixels wide. In general this resolution limit is determined by the greater of two criteria: Either $\gtrsim 2$ pixels wide to resolve a particle or diffraction limited resolution as found by,

$D_{p}=\frac{2.44 \lambda z_{\max }}{D_{a p}}$

where $D_{p}$ is the limiting resolution diameter of the particle, $\lambda$ is the wavelength, $z_{\max }$ is the furthest distance in the sample volume from the camera, and $D_{a p}$ is the scale diameter of the 
aperture or camera (Fugal et al., 2009). For our system parameters and a maximum reconstruction depth of $75 \mathrm{~mm}$ we obtain $D_{p}=23.4 \mu \mathrm{m}$. The maximum detection size is around $1.0 \mathrm{~mm}$ (or some fraction of the detector size) as determined by our automated hologram processing code's ability to reliably bring such a large particle in focus (Fugal et al., 2009).

The particle sizes from HOLODEC are calculated by counting the number of pixels contained in each focused particle and calculating an equivalent diameter for a circle of equal area. For spherical particles this pixel counting method gives a precision approximately equal to the square root of the pixel size, or $\sim 2.2 \mu \mathrm{m}$ (Lu et al., 2008). Fugal et al. (2004) and Pu et al. (2005) discuss more on determining the accuracy of sizing particles using digital in-line holography.

For the purposes of determining how accurately HOLODEC can measure particle size distributions, we made thousands of simulated holograms with the same hologram size, pixel size, wavelength, and same particle sizes and depth positions as real HOLODEC holograms. The simulated holograms had only round particles and had a number density an order of magnitude higher than the real holograms taken with HOLODEC. The holograms were made using an analytical expression for the far-field diffraction pattern for a unit amplitude plane wave diffracted about a circular aperture (Goodman, 1996). We confirmed with these simulations that HOLODEC holograms and the particular reconstruction algorithm we use (Fugal et al., 2009) recovers the original particle size distribution for particle diameters ranging from $23 \mu \mathrm{m}$ to $100 \mu \mathrm{m}$ (see Sect. 4).

Finally, as with every instrument that counts particles, HOLODEC's ability to measure ice particle size distributions and number densities is limited by the uncertainty inherent in counting statistics. As larger particles tend to have much smaller number densities, this means that while HOLODEC can detect and measure the size of larger ice particles, its sample rate limits its ability to reliably measure the number density of very large ice particles. Again, a faster or larger camera in HOLODEC would yield a much higher volume sample rate and more accurate counting statistics. The number density error bars shown in subsequent plots are one standard deviation assuming Poisson counting statistics.

\section{Data sample}

HOLODEC flew onboard the NSF/NCAR C-130 Q Hercules research aircraft over Colorado on nine flights in August and September 2003. This was an instrument-testing campaign, IDEAS 3 (Instrument Development and Education in the Atmospheric Sciences, phase 3) and therefore much of the flight time was devoted to debugging and evaluation. From the subset of times when HOLODEC was recording clear holograms (some holograms were not clear, primarily as a result of the formation of condensation or ice deposition on windows), we select times during which there is a likelihood of finding ice particles as indicated from data taken with the FSSP and 2D-C instruments. We analyzed $\sim 7400$ holograms or $\sim 8$ flight-minutes ( $\sim 48 \mathrm{~km}$ flight path) taken on the 2003-09-17 Research Flight, $\sim 10300$ holograms or $\sim 11$ $\min (\sim 66 \mathrm{~km}$ flight path) taken on the 2003-09-05 Research Flight, and $\sim 5500$ holograms or $\sim 6 \mathrm{~min}(\sim 36 \mathrm{~km}$ flight path) taken on the 2003-09-19 Research Flight. Together the data consist of $\sim 23200$ holograms reconstructed to find around 30,300 particles in the size range $23 \mu \mathrm{m}$ to $980 \mu \mathrm{m}$ equivalent area diameter. The holograms for the 2003-09-19 Research Flight were of clear air and are used to measure the noise floor of the HOLODEC instrument.

\subsection{Cloud conditions in data sample}

Our purpose in selecting time segments from these flight data sets is to examine HOLODEC's ability to measure cloud particle size distributions under a variety of cloud conditions. Figure 4 shows number densities of particles sampled by the 2D-C ( $\geq 200 \mu \mathrm{m})$ and FSSP $(\geq 23 \mu \mathrm{m})$ for the data sets mentioned above as well as times at which HOLODEC recorded clear holograms. These time periods are of interest because the low number densities measured by the 2D-C instrument indicate that there are few large ice particles to shatter on the leading probe parts, and the high number densities measured by the FSSP above $23 \mu \mathrm{m}$ (the detection limit of HOLODEC) indicate we should have sizable number densities of cloud particles for HOLODEC to measure. Figure 5 shows total water and liquid water content as measured by the Nevzorov probe. We use the Nevzorov probe as an indicator of the phase of cloud water content (Isaac et al., 2006; Cober et al., 2001; Korolev et al., 1998b).

Figures 4 and 5 have bars identifying the times for which panels in Figs. 8 and 9 show size distributions. These times (a) to (g) encompass most of the available data from the test flights for HOLODEC, meaning times when the instrument was recording clean holograms and the aircraft was in cloud. They represent a variety of cloud conditions, ranging from all ice to all liquid, and varying concentrations of large ice particles. Qualitatively speaking, segments (a) and (b) are nearly pure ice, with some indication of the presence of large ice crystals from the 2DC; segments (c) and (d) are mixed phase, with liquid water contents well below $50 \%$ of the total water content, but also with very little or no indication of large ice crystals (duly noting that a residual liquid signal is possible even in an all-ice cloud; cf. Korolev et al., 1998b); segment (e) is the only cloud segment with no indication of any ice, as well as no large particles from the 2DC; and segments (f) and (g) are mixed phase with modest densities of large ice crystals. 

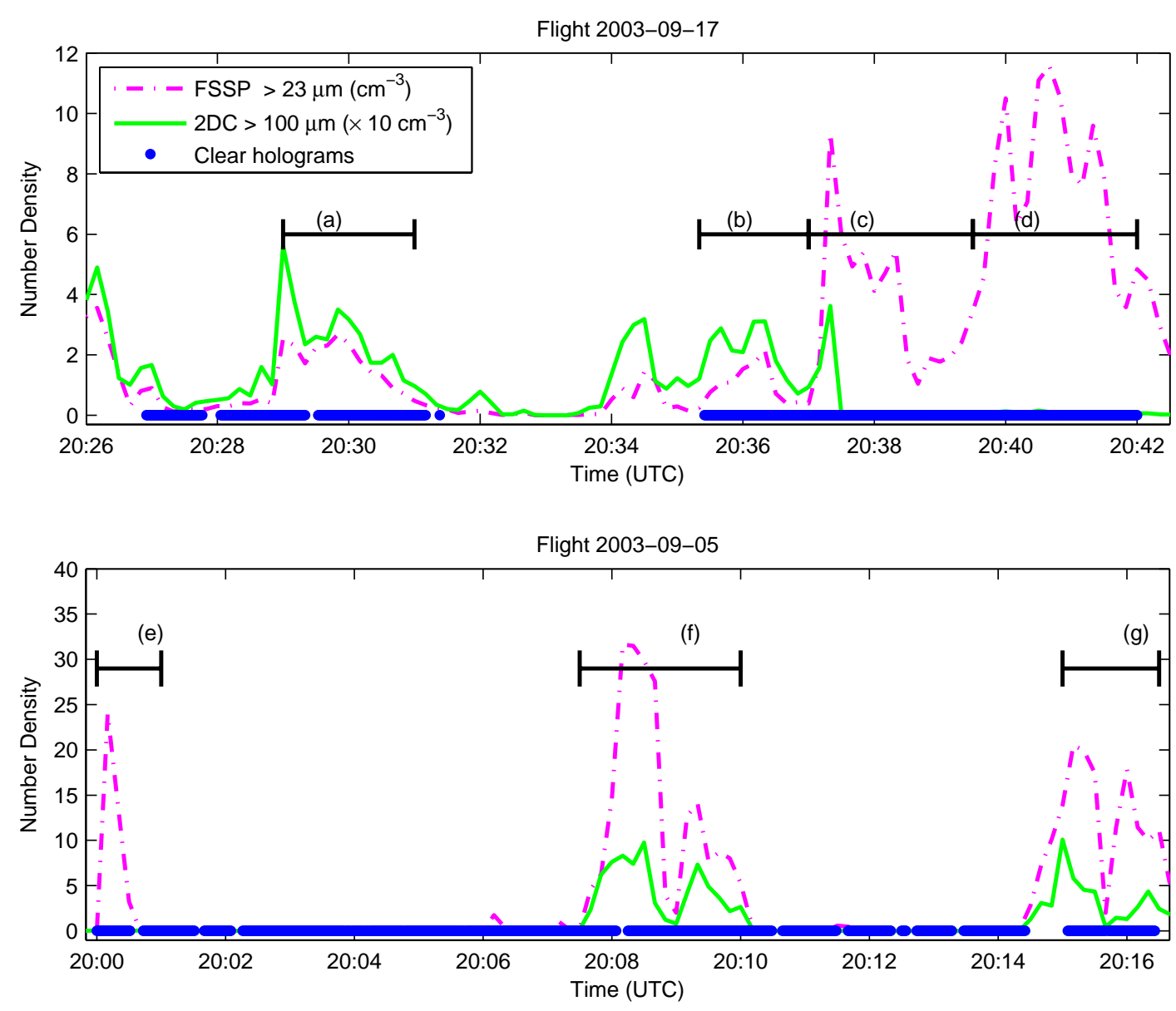

Fig. 4. Particle number densities from the FSSP and the 2D-C instruments for the 2003-09-17 and 2003-09-05 Research Flights. Also shown are the times where HOLODEC recorded clear holograms. The brackets labeled (a) to (g) denote regions with varying microphysical properties for which HOLODEC size distributions have been calculated (cf. Figs. 8 and 9).

\subsection{Corrections to FSSP sizing of ice particles}

HOLODEC size distributions can be compared to the FSSP size distributions quantitatively when there is evidence that the size range being compared consists primarily of liquid water. When ice is present in significant quantities, however, a qualitative comparison is possible by assuming an ice crystal shape and correcting the FSSP data accordingly. Of course different particle shapes and orientations yield different corrections, so the point is to give an estimate of plausible variability in the FSSP size distribution. The FSSP provides an estimate of particle size by measuring the intensity of forward scattered laser light collected between $5^{\circ}$ and $14^{\circ}$. The size of a particle is inferred by calculating, for a given particle size, the intensity of the integrated forward scattered light assuming a spherical shape and an index of refraction for liquid water. Ice particles, however, have a different index of refraction and usually are not spherical. A reasonable approximation for the shape of small ice particles is a droxtal resembling a faceted sphere (Field et al., 2003a). Using a library of light scattering calculations for randomly oriented small droxtals provided by P. Yang (Yang et al., 2003; Zhang et al., 2004), we calculated an approximate correction of forward scattering from spherical water drops to droxtals of the same size. As a heuristic, we note that, on average, randomly-oriented non-spherical particles scatter less light in the forward direction than spherical particles of equal volume. Thus the FSSP detects less light for a non-spherical particle, all else being equal, and underestimates its size. A correction for this effect will shift the FSSP size bins calibrated for spherical particles to larger effective sizes for non-spherical particles. While this correction is approximate and assumes a particular shape of small ice crystals, it provides at least one qualitative comparison for the size distributions measured with HOLODEC.

\section{Results}

We evaluate the HOLODEC instrument by performing automated calculation of cloud particle size distributions, total particle number density, and total water content, in different 

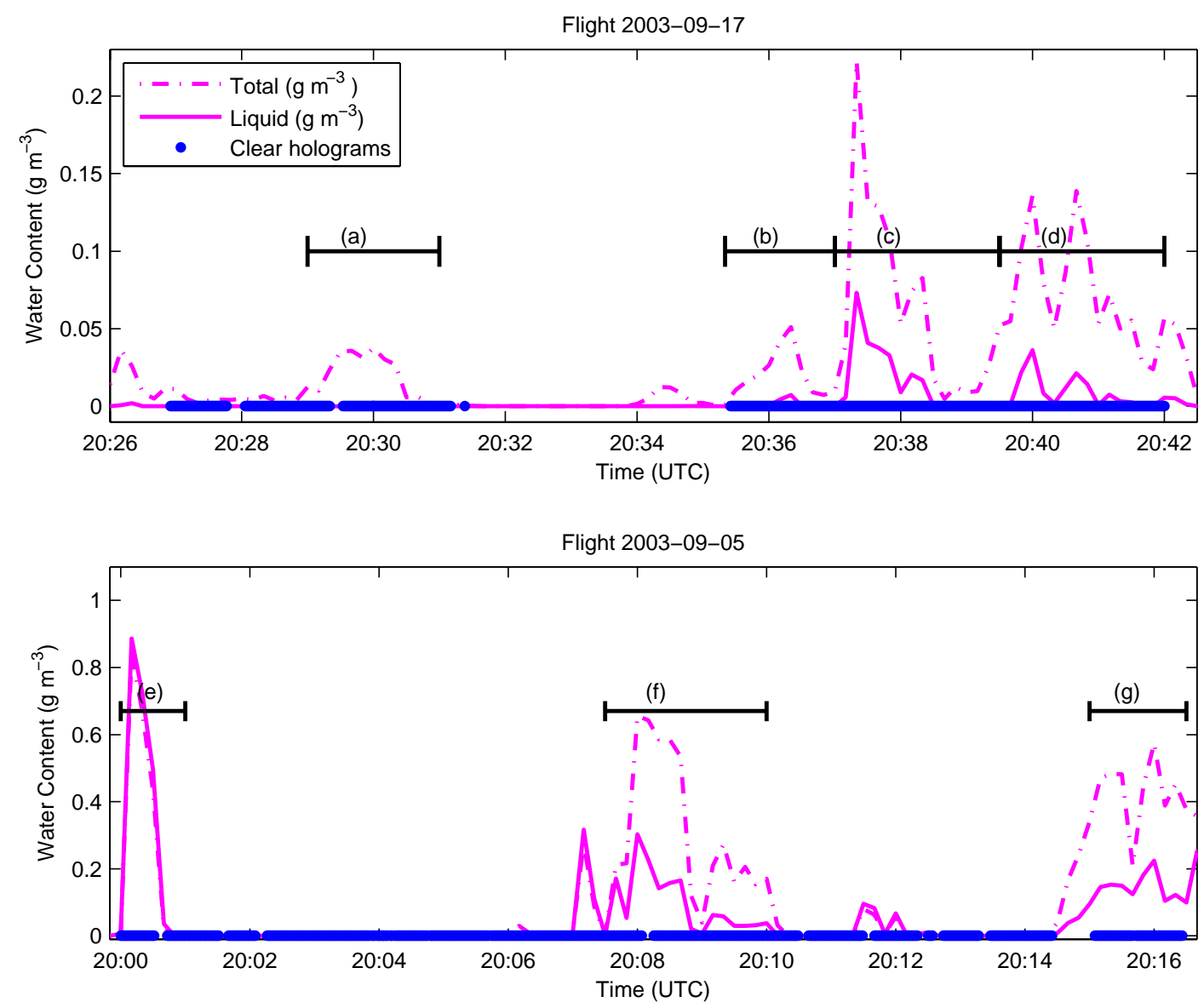

Fig. 5. Total (ice plus liquid) and liquid water content for the 2003-09-17 and 2003-09-05 Research Flights as measured by the Nevzorov probe. The brackets labeled (a) to (g) denote regions with varying microphysical properties for which HOLODEC size distributions have been calculated (cf. Figs. 8 and 9).

cloud conditions. To begin with, we verified the null measurement of HOLODEC by reconstructing holograms of clear air from Research Flight 2003-09-19. The results were 125 detections out of 3913 holograms in the particle size range $>23 \mu \mathrm{m}$ with a maximum particle size of $57 \mu \mathrm{m}$. This represents an average number density of 0.08 particles $\mathrm{cm}^{-3}$ which is deep in the noise for typical number densities of particles in this size range. Figure 6 compares the number density measured by HOLODEC with that measured by the FSSP for Research Flights 2003-09-17 (top panel) and 200309-05 (bottom panel). Also shown is the number density measured by HOLODEC after rejecting holograms containing shattered particles (HOLODEC Cor.), and the number density from the ice-corrected FSSP (FSSP Ice Cor.).

Figure 7 compares total water content calculated from HOLODEC to that measured by the Nevzorov probe and, for reference, to the liquid water content measured by the King Probe. HOLODEC water contents are to be interpreted as estimates because they are based on the assumption that all particles are liquid water spheres. With an appropriate shape condition this certainly could be improved, both by using the shape and by using the density of ice. The density of ice versus liquid water alone suggests that the HOLODEC water contents will be overestimated by at least $10 \%$ when ice is the predominant phase. It is also important to note that the Nevzorov probe is known to underestimate water contents when large ice crystals are present (Isaac et al., 2006).

Figures 8 and 9 show HOLODEC and FSSP size distributions from Research Flights 2003-09-17 and 2003-09-05. Also shown are a HOLODEC size distribution corrected by excluding holograms with detected shards of shattered particles (cf. Sect. 2.2, and FSSP size distributions corrected for ice particle sizes as discussed in Sect. 3.2. We have omitted the 2D-C instrument size distributions because of their large size distribution uncertainties for particle diameters $\lesssim 100 \mu \mathrm{m}$. The error bars for the HOLODEC size distributions correspond to one standard deviation assuming Poisson sampling statistics (error bars are not shown for the shattering-corrected size distribution for clarity). For the purpose of intercomparison, the total number of sampled particles is also indicated by the number in the upper right corner of each panel. 

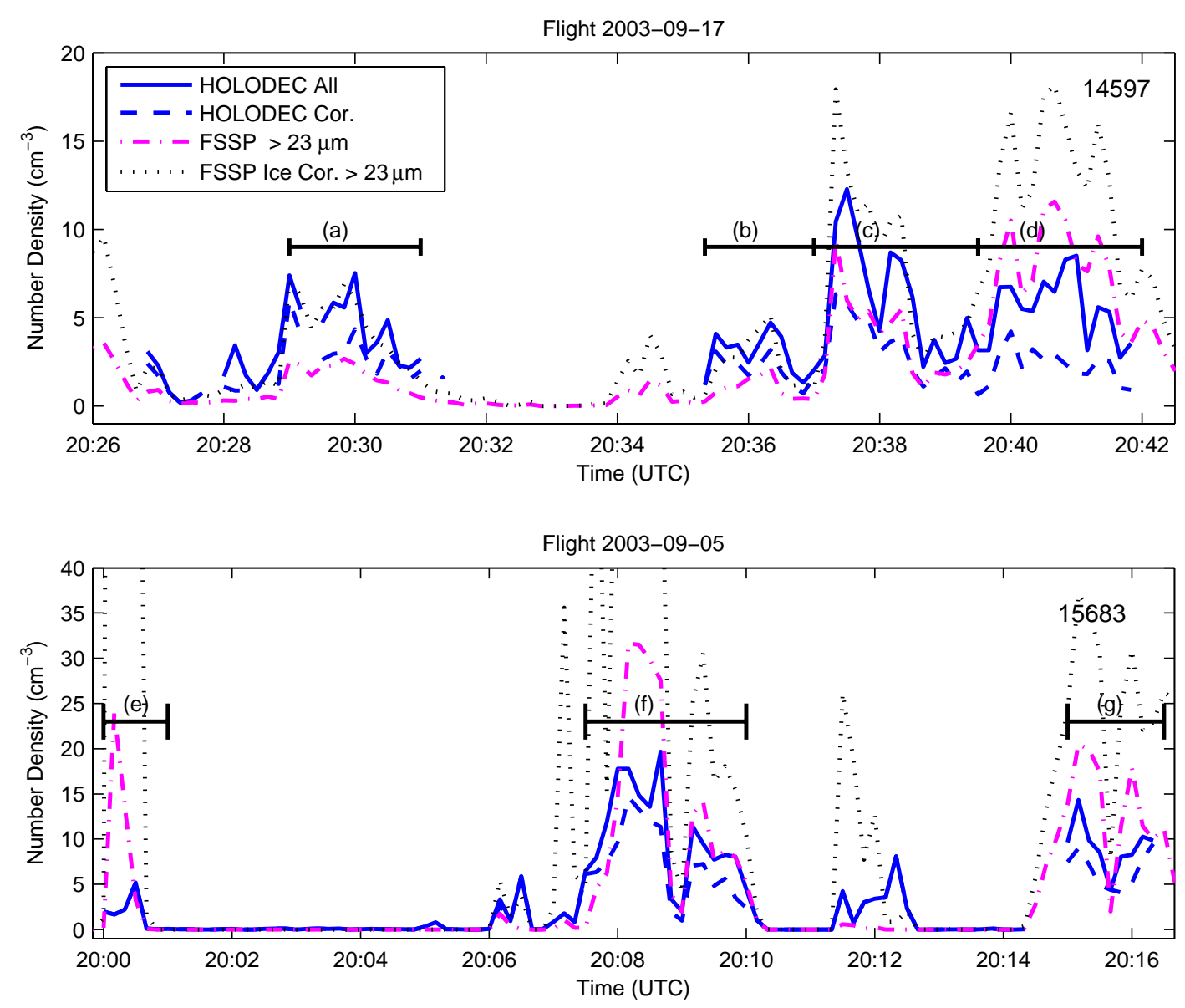

Fig. 6. Number densities for $10 \mathrm{~s}$ intervals from the FSSP and HOLODEC for the research flights indicated. HOLODEC All shows the number density for all detected particles while HOLODEC Cor. shows the same but excluding holograms with detected shards of shattered particles. The number in the upper right of the panels is the number of cloud particles used to calculate the HOLODEC number density of all particles for the whole time period of each panel.

While HOLODEC can detect from $23 \mu \mathrm{m}$ up to $1.0 \mathrm{~mm}$ size particles, we do not show size distribution estimates above $100 \mu \mathrm{m}$ in Figs. 8 and 9 because the error in counting statistics is extremely large. However, larger particles are observed and sized correctly, so future holography-based instruments with larger sample volumes will enable size distributions to be extended. This ability to detect ice crystals with size $\geq 100 \mu \mathrm{m}$ is illustrated in Fig. 10, which shows a collection of such particles from Research Flight 2003-0905 . These particles are presented as they are reconstructed by the automated reconstruction and particle finding algorithm (Fugal et al., 2009). (A similar collection of images for Research Flight 2003-09-17 is shown in Fugal et al. (2009, Fig. 6).) The wavy non-uniform background about these particles is the virtual image of each ice particle (Fugal et al., 2004). As discussed by Fugal et al. (2009), the shape of particles in reconstructed images smaller than about 10 pixels across appear more like circles with few discernible features such as facets. Because the diffraction limited resolution of HOLODEC is $\sim 23 \mu \mathrm{m}$ (about 5 pixels across) this limit of 10 pixels is approximately twice the diffraction limit. While we have not attempted to use a phase discrimination algorithm in our analysis, we expect that such algorithms would have success in classifying particles larger than about 10 pixels or a few times the diffraction limited resolution.

\section{Discussion}

The agreement between HOLODEC and the ice-corrected FSSP is remarkably good during time segments (a) and (b), where the Nevzorov probe indicates all ice conditions. This agreement can be seen in both the number density time series (Fig. 6) and in the size distributions (Fig. 8). After correction for shattering, however, the HOLODEC number densities are reduced by up to a factor of two. The total water content calculated from the shattering-corrected HOLODEC measurements is consistently above, but following the same trends as the Nevzorov total water content. This is not surprising given the known problems with Nevzorov ice crystal 
Flight 2003-09-17

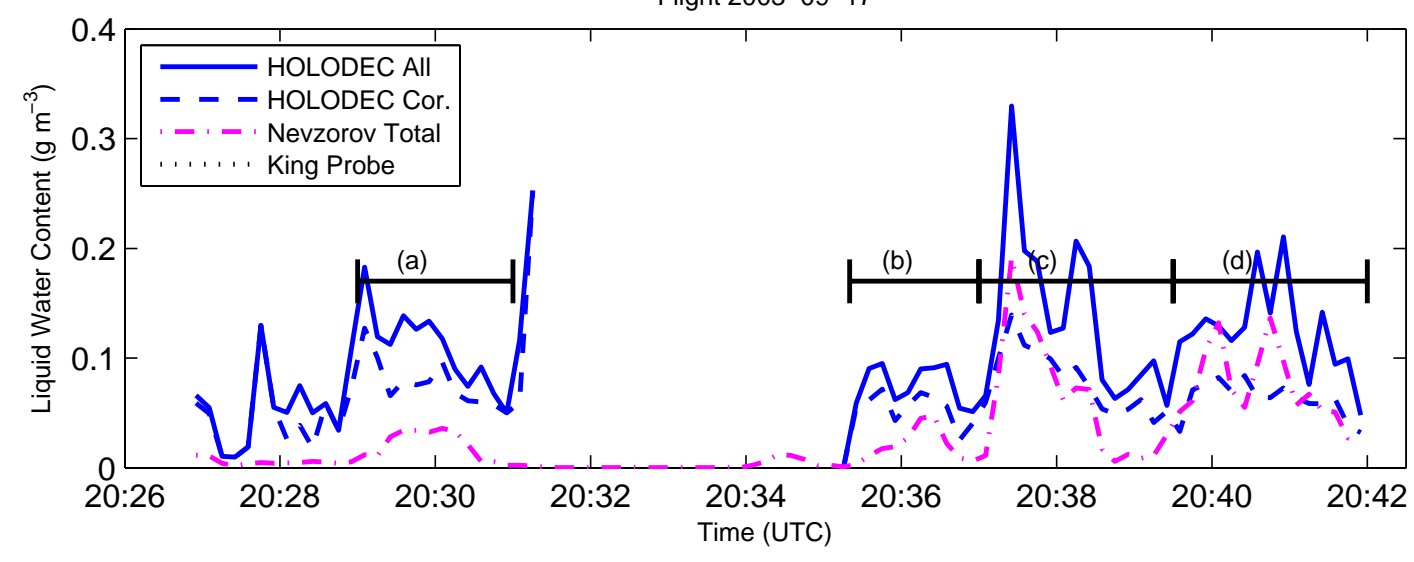

Flight 2003-09-17

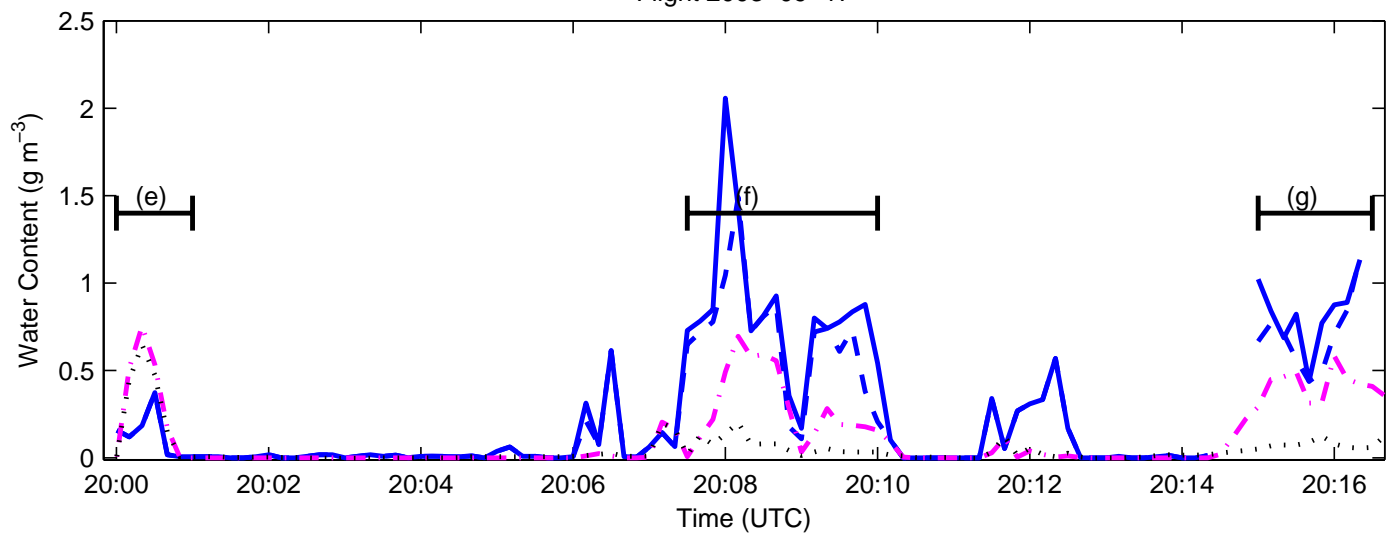

Fig. 7. Total water content for $10 \mathrm{~s}$ intervals from the Nevzorov probe, liquid water content (LWC) from the King Probe, and LWC calculated from HOLODEC data for the Research Flights indicated (assuming all particles are liquid water spheres). There was no valid King Probe data from Research Flight 2003-09-17.

sampling (Isaac et al., 2006) and the assumption of liquid water spheres in the HOLODEC calculation.

Segments (c) and (d) from mixed phase clouds with minimal large particles from the 2DC do not show agreement with the ice-corrected FSSP. For example, in Fig. 6 the uncorrected HOLODEC data lie between the two FSSP limits for segment (c) and just below the uncorrected FSSP for segment (d). The same effect is observed in the size distributions for segments (c) and (d) in Fig. 8. In spite of the fact that there is no indication of particle larger than $100 \mu \mathrm{m}$, the HOLODEC shattering correction is significant for both segments. The shattering-corrected HOLODEC water contents are in reasonable agreement with the Nevzorov water contents, so it is likely that the ambiguity in the FSSP comparisons results from a lack of knowledge of how liquid water and ice are partitioned in size, as well as the acknowledged uncertainty in how the FSSP signal should be corrected (e.g. shape uncertainties).

Segment (e) is quite important because it is all liquid water and therefore provides a direct comparison with the FSSP. There was no indication of large particles or ice, which is consistent with the HOLODEC size distributions (uncorrected and shatter-corrected) showing no difference in Fig. 9. The HOLODEC and FSSP size distributions have similar slopes but particle number densities are progressively underestimated by HOLODEC with decreasing droplet diameter. This explains the disparity in total number density observed in segment (e) of Fig. 6 as well as the reasonable (factor of 2) agreement in liquid water content in Fig. 7, the latter being more heavily influenced by the large droplets. We interpret the HOLODEC size distribution as being a roll-off in the particle detection ability. The theory used to estimate the detection limit of $23 \mu \mathrm{m}$ is not exact and one would expect that the limit is, in fact, not a threshold but a transition. Nevertheless, we find the general agreement of the measurements to be a strong indication that the simple theory does indeed capture the essential physical processes involved.

The last two segments, (f) and (g), correspond to mixed phase conditions with somewhat greater liquid-to-total water ratios and also with significant numbers of large particles (likely ice) as detected by the 2DC. It is perhaps surprising, therefore, that the shattering-corrected HOLODEC size 
(a) 20:29:00 to $20: 31: 00$

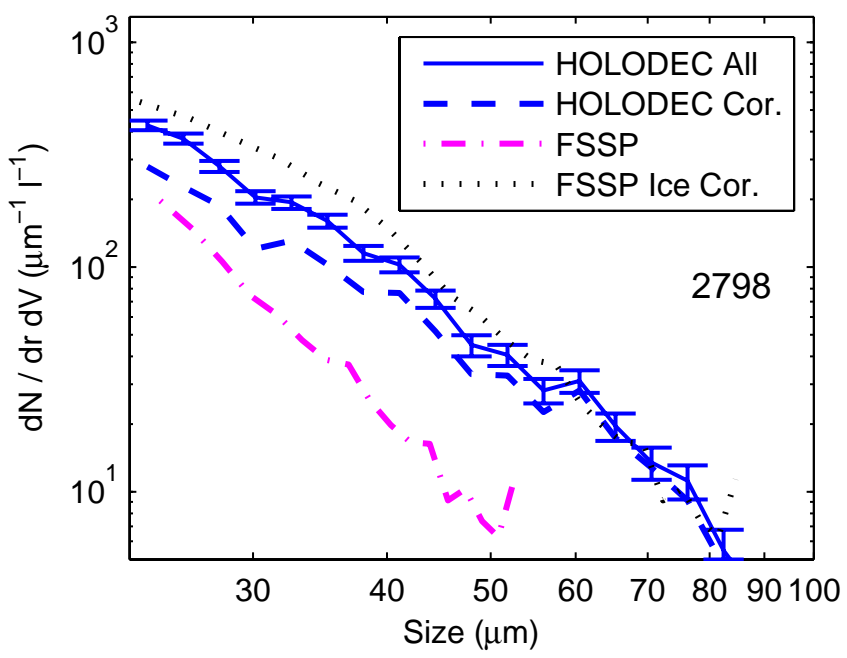

(c) $20: 37: 00$ to $20: 39: 30$

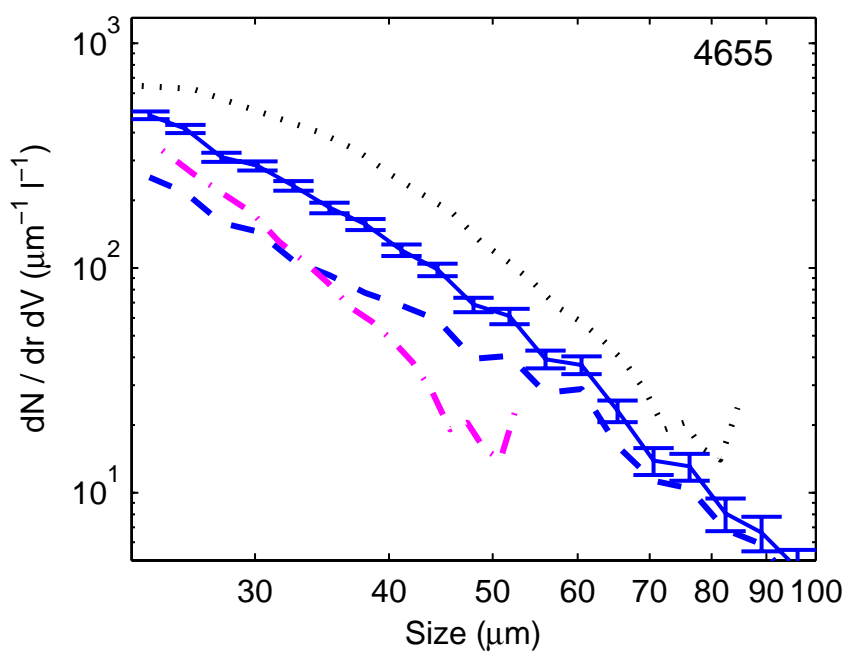

(b) $20: 35: 20$ to $20: 37: 00$

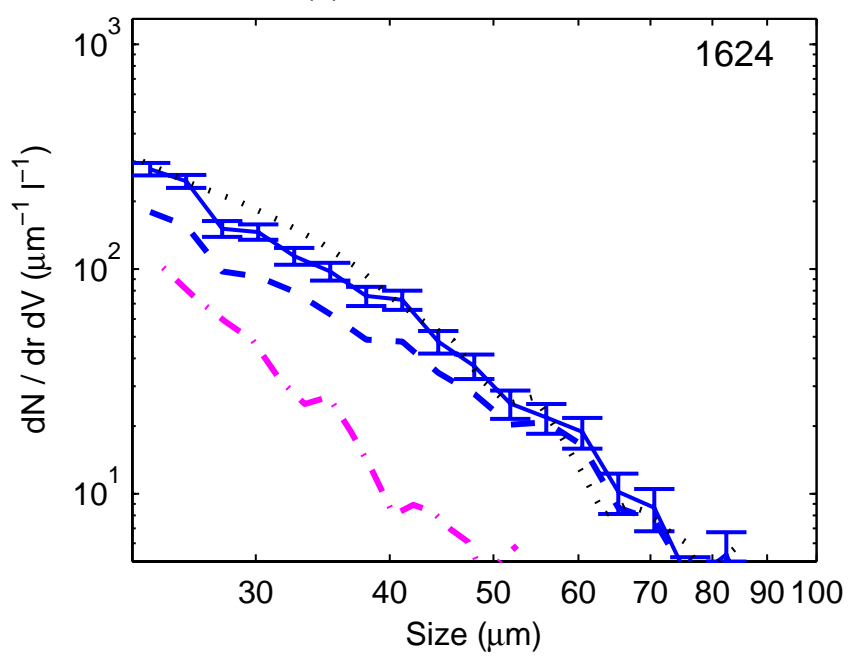

(d) $20: 39: 30$ to $20: 42: 00$

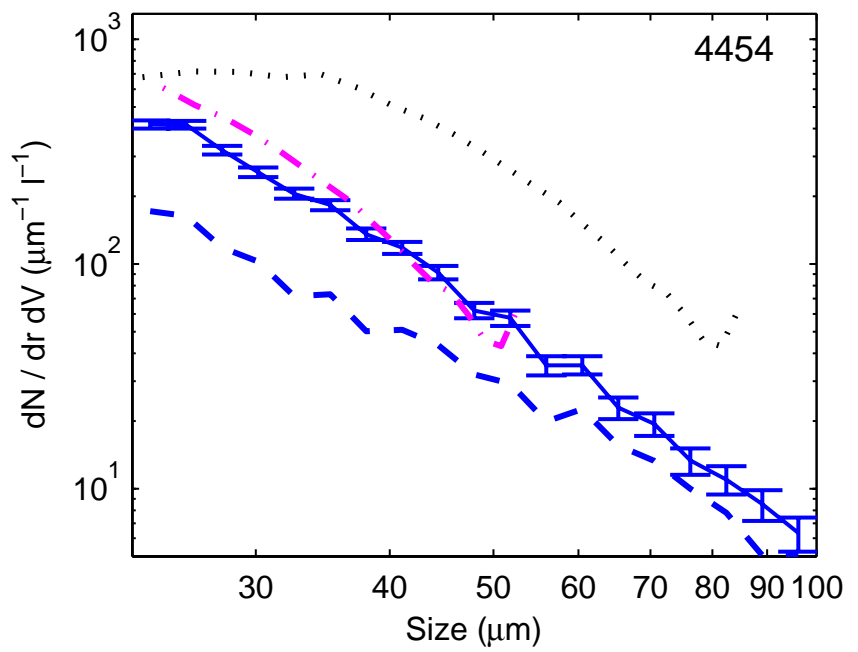

Fig. 8. Cloud particle size distributions for Research Flight 2003-09-17 during the time periods shown above each panel, corresponding to segments (a) through (d). HOLODEC distributions are shown for all detected particles and corrected by excluding holograms with shattered particles. FSSP distributions are shown for both standard and corrected for ice particle sizing as described in Sect. 3.2. The error bars correspond to a one standard deviation error assuming Poisson counting statistics. The number in the upper right of each panel is the total number of cloud particles used to calculate the HOLODEC size distribution (uncorrected).

distributions shown in Fig. 9 are not greatly different from the uncorrected HOLODEC distributions. The more prominent presence of liquid water does, however, appear to be consistent with the reasonable agreement between the uncorrected FSSP and the uncorrected HOLODEC distributions.

To sum up the data discussion, in spite of the fact that there are great uncertainties in interpreting FSSP size distributions when ice is present, in all time periods the HOLODEC number density trends with the FSSP number density quite well. HOLODEC water contents also follow the trends of the Nevzorov total water content, which we find promising given the uncertainties in calculating water contents without distinguishing between liquid water and ice. The size distributions shown in Figs. 8 and 9 illustrate the performance of HOLODEC under a variety of microphysical conditions. Time segments (a) and (b) (nearly all ice) show reasonable agreement between the HOLODEC size distribution and ice corrected FSSP size distribution. For the mixed phase segments the HOLODEC size distributions generally lie between the FSSP and ice-corrected FSSP size distributions. In mixed-phase clouds, one ideally should partition ice and liquid water as a function of particle size and ice particle habit. But without some assumption to justify a particular partition, there is no rationale for determining what weighting 
(e) 20:00:00 to $20: 01: 00$

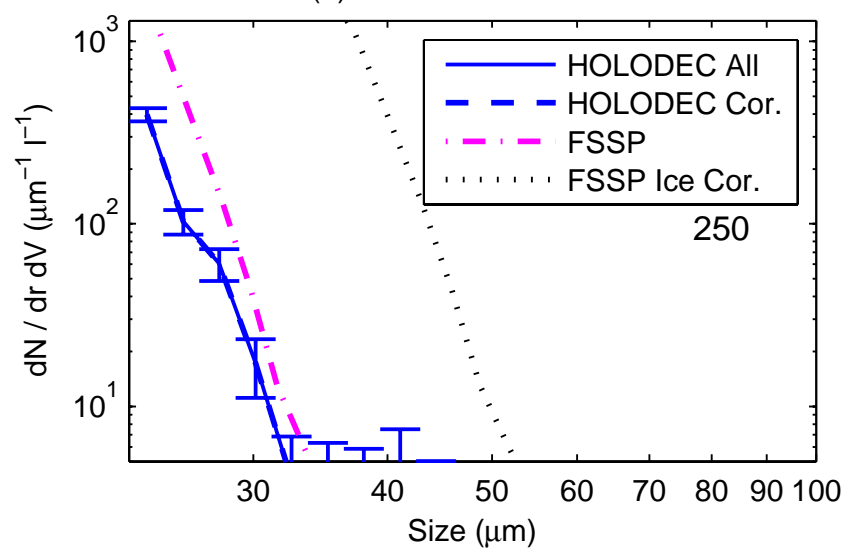

(f) $20: 07: 30$ to $20: 10: 00$

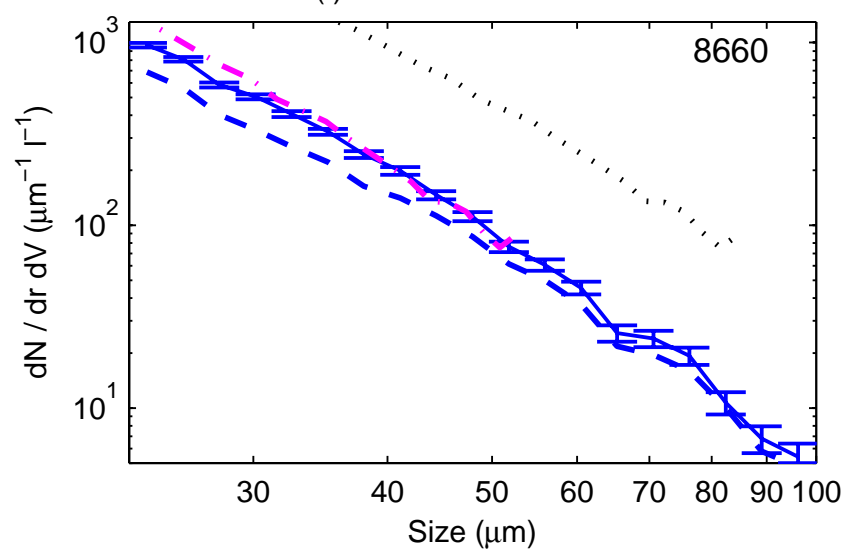

(g) $20: 15: 00$ to $20: 16: 30$

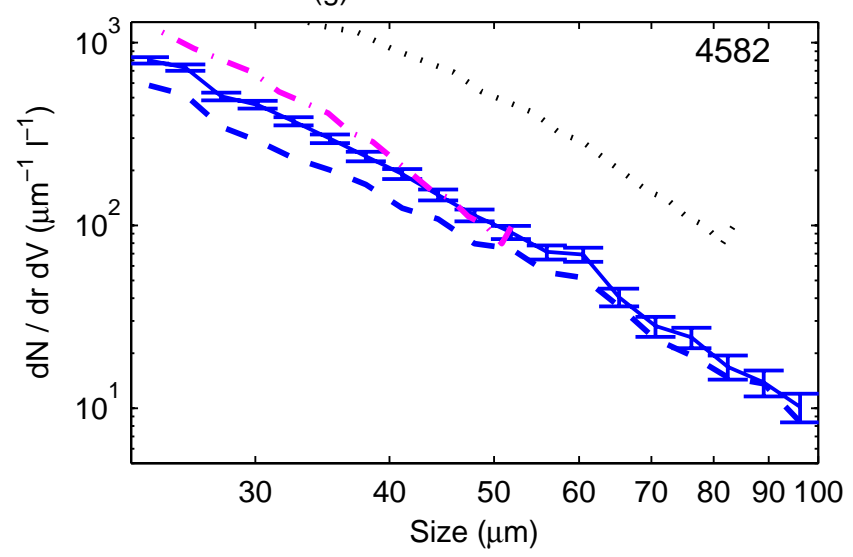

Fig. 9. As in Fig. 8, but for Research Flight 2003-09-05, segments (e) through (g).

of uncorrected and corrected FSSP sizes to use. The utility of this method of correcting for ice particles may be in estimating a plausible upper bound on ice, corresponding to glaciated conditions (e.g. as indicated by the Nevzorov probe). In all segments (except for (e) with all liquid water) there is an observable correction in the HOLODEC data

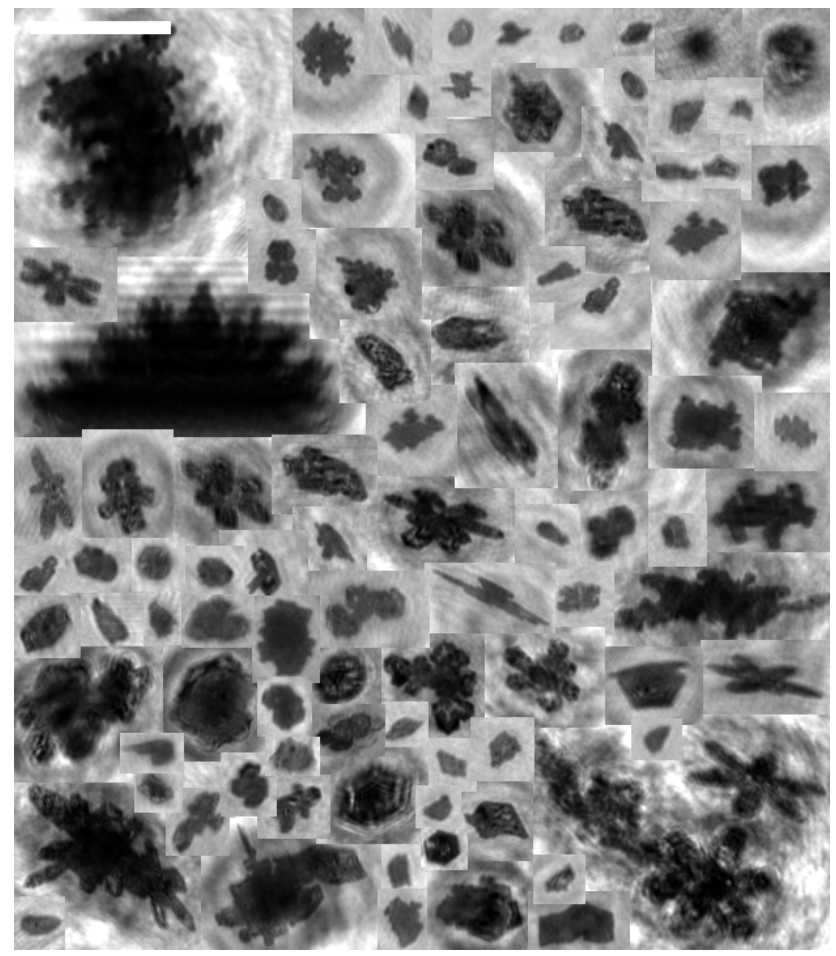

Fig. 10. Reconstructed images of Ice particles larger than $100 \mu \mathrm{m}$ in equivalent diameter from Research Flight 2003-09-05. They appear as reconstructed by the automated particle finding algorithm. The white scale bar in the upper left is $0.5 \mathrm{~mm}$ in length.

due to particle shattering. We note in passing that the shattered particles (the difference between the blue dashed and blue solid lines shown in Figs. 8 and 9) are typically small ice particles $\lesssim 70 \mu \mathrm{m}$ equivalent diameter. Finally, the all liquid cloud sample in segment (e) suggests that the resolution estimate obtained in Sect. 2.1 is reasonable, but that a roll-off factor likely should be determined in laboratory tests. Taken together, these results indicate that the HOLODEC instrument can measure reasonable cloud particle size distributions in the size range $\sim 23 \mu \mathrm{m}$ to $100 \mu \mathrm{m}$, and reasonable ice sizes and shapes above $100 \mu \mathrm{m}$.

\section{Summary}

In summary, we have shown that HOLODEC, an instrument using digital inline holography, and the reconstruction algorithm described by Fugal et al. (2009) can detect cloud particles, find their 3-D positions, calculate their sizes, and give 2-D images in an automated fashion suitable for large fieldcampaign data sets. From these results, size distributions and number densities can be calculated.

We have shown that we get similar size distributions from HOLODEC and an FSSP in mixed phase cloud particle conditions. We get similar agreement in pure ice conditions given the uncertainty in correcting FSSP data for 
non-spherical ice particles. We also note the ability to detect holograms with shattered ice particles even with our simple model of searching for highly localized clusters along the optical axis and thus obtain more accurate size distributions.

The digital holographic method, as implemented here, allows a volume sample rate that is independent of particle size and air speed. And with its associated hologram reconstruction and particle finding algorithm, we are able to find particles in a large size range limited only by a few pixels wide for small particles, and some fraction of the size of the camera for large particles. While holograms require a much longer processing time than instruments that offer real time results, holograms provide more information than current optical cloud particle instrumentation. Furthermore, as with any computational problem, obstacles related to hologram construction time will erode and eventually vanish as computation speeds and algorithm development progress. HOLODEC is a prototype instrument designed to validate the ability and utility of digital holography for cloud particle measurements. Future versions of this instrument would be improved by including a camera with a faster frame rate or larger image size, thereby increasing the instantaneous sample size and continuous sample rate. This combined with more refined algorithms will improve the ability to obtain accurate cloud particle size distributions with better exclusion of shattered particle contamination, and to provide other cloud particle measurements of interest (e.g. cloud particle spatial distribution).

Acknowledgements. This work is supported by an NSF Graduate Research Fellowship, a NASA Earth System Science Fellowship, a Michigan Space Grant Consortium Graduate Fellowship, and NSF Grant ATM-0535488. We thank the staff of NCAR's Research Aviation Facility for aiding us in analyzing the data from other aircraft probes taken during the IDEAS 3 campaign. We also thank P. Yang for providing the library of scattering calculations for droxtals. We thank A. Cooper, P. Field, and D. Rogers for helpful comments and discussion.

Edited by: M. Wendisch

\section{References}

Baum, B. A., Heymsfield, A. J., Yang, P., and Bedka, S.: Bulk scattering properties for the remote sensing of ice clouds, Part I: Microphysical data and models, J. Appl. Meteorol., 44, 18851895, 2005a.

Baum, B. A., Yang, P., Heymsfield, A. J., Platnick, S., King, M. D., $\mathrm{Hu}$, Y.-X., and Bedka, S.: Bulk scattering properties for the remote sensing of ice clouds, Part II: Narrowband models, J. Appl. Meteorol., 44, 1896-1911, 2005 b.

Baumgardner, D. and Korolev, A. J.: Airspeed corrections for optical array probe sample volumes, J. Atmos. Ocean. Tech., 14, 1224-1229, 1997.

Borrmann, S. and Jaenicke, R.: Application of microholography for ground-based in situ measurements in stratus cloud layers: a case study, J. Atmos. Ocean. Tech., 10, 277-293, 1993.
Brown, P. R. A.: Use of Holography for Airborne Cloud Physics Measurements, J. Atmos. Ocean. Tech., 6, 293-306, 1989.

Cober, S. G., Isaac, G. A., and Korolev, A. V.: Assessing the Rosemount Icing Detector with in situ measurements, J. Atmos. Ocean. Tech., 18, 515-528, 2001.

Field, P. R., Baran, A. J., Kaye, P. H., Hirst, E., and Greenaway, R.: A test of cirrus ice crystal scattering phase functions, Geophys. Res. Lett., 30, 1752, doi:10.1029/2003GL017482, 2003a.

Field, P. R., Wood, R., Brown, P. R. A., Kaye, P. H., Hirst, E., Greenway, R., and Smith, J. A.: Ice particle interarrival times measured with a fast FSSP, J. Atmos. Ocean. Tech., 20, 249-261, 2003 b.

Field, P. R., Heymsfield, A. J., and Bansemer, A.: Shattering and particle interarrival times measured by optical array probes in ice clouds, J. Atmos. Ocean. Tech., 23, 1357-1371, 2006.

Fugal, J. P., Shaw, R. A., Saw, E. W., and Sergeyev, A. V.: Airborne digital holographic system for cloud particle measurements, Appl. Optics, 43, 5987-5995, 2004.

Fugal, J. P., Schulz, T. J., and Shaw, R. A.: Practical methods for automated reconstruction and characterization of particles in digital in-line holograms, Meas. Sci. Technol., 20, 075501, doi:10.1088/0957-0233/20/7/075501, 2009.

Gardiner, B. A. and Hallett, J.: Degradation of in-cloud forward scattering spectrometer probe measurements in the presence of ice particles, J. Atmos. Ocean. Tech., 2, 171-180, 1985.

Gayet, J.-F., Febvre, G., and Larsen, H.: The reliability of the PMS FSSP in the presence of small ice crystals, J. Atmos. Ocean. Tech., 13, 1300-1310, 1996.

Goodman, J.: Introduction to Fourier Optics, McGraw Hill, Boston, 2 edn., 1996.

Isaac, G. A., Korolev, A. V., Strapp, J. W., Cober, S. G., Boudala, F. S., Marcotte, D., and Reich, V. L.: Assessing the collection efficiency of natural cloud particles impacting the Nevzorov total water content probe, proceedings of 44th Aerospace Sciences Meeting and Exhibit, Am. Inst. of Aeronaut. and Astronaut., Reno, Nev., 9-12 Jan., 2006.

Korolev, A.: Reconstruction of the sizes of spherical particles from their shadow images, Part I: Theoretical considerations, J. Atmos. Ocean. Tech., 24, 376-389, 2007.

Korolev, A. and Isaac, G.: Shattering during sampling by OAPs and HVPS, Part I: snow particles, J. Atmos. Ocean. Tech., 22, 528542, 2005.

Korolev, A. V., Strapp, J. W., and Isaac, G. A.: Evaluation of the accuracy of PMS optical array probes, J. Atmos. Ocean. Tech., 15, 708-720, 1998a.

Korolev, A. V., Strapp, J. W., Isaac, G. A., and Nevzorov, A. N.: The Nevzorov airborne hot-wire LWC-TWC probe: Principle of operation and performance characteristics, J. Atmos. Ocean. Tech., $15,1495-1510,1998 b$.

Kozikowska, A., Haman, K., and Supronowicz, J.: Preliminary results of an investigation of the spatial distribution of fog droplets by a holographic method, Q. J. Roy. Meteor. Soc., 110, 65-73, 1984.

Lawson, R. P. and Cormack, R. H.: Theoretical design and preliminary tests of 2 new particle spectrometers for cloud microphysics research, Atmos. Res., 35, 315-348, 1995.

Lawson, R. P., O'Connor, D., Zmarzly, P., Weaver, K., Baker, B., Mo, Q., and Jonsson, H.: The 2D-S (Stereo) probe: design and preliminary tests of a new airborne, high-speed, high-resolution 
particle imaging probe, J. Atmos. Ocean. Tech., 23, 1462-1477, 2006.

Lu, J., Fugal, J. P., Nordsiek, H., Saw, E. W., Shaw, R. A., and Yang, W.: Lagrangian particle tracking in three dimensions via singlecamera in-line digital holography, New J. Phys., 10, 125015, doi: 10.1088/1367-2630/10/12/125013, 2008.

McFarquhar, G. M., Um, J., Freer, M., Baumgardner, D., Kok, G. L., and Mace, G.: Importance of small ice crystals to cirrus properties: Observations from the Tropical Warm Pool International Cloud Experiment (TWP-ICE), Geophys. Res. Lett., 34, L13803, doi:10.1029/2007GL029865, 2007.

Nagel, D., Maixner, U., Strapp, W., and Wasey, M.: Advancements in techniques for calibration and characterization of in situ optical particle measuring probes, and applications to the FSSP-100 probe, J. Atmos. Ocean. Tech., 24, 745-760, 2007.

Pu, S. L., Allano, D., Patte-Rouland, B., Malek, M., Lebrun, D., and Chen, K. F.: Particle field characterization by digital in-line holography: 3D location and sizing, Exp. Fluids, 39, 1-9, 2005.

Raupach, S. M. F., Vossing, H. J., Curtius, J., and Borrman, S.: Digital crossed-beam holography for in situ imaging of atmospheric particles, J. Opt. A.-Pure Appl. Op., 8, 796-806, 2006.
Strapp, J. W., Albers, F., Reuter, A., Korolev, A. V., Maixner, U., Rashke, E., and Vukovic, Z.: Laboratory measurements of the response of a PMS OAP-2DC, J. Atmos. Ocean. Tech., 18, 11501170, 2001.

Thompson, B. J.: Holographic particle sizing techniques, J. Phys. E. Sci. Instrum., 7, 781-788, 1974.

Trolinger, J. D.: Particle field holography, Opt. Eng., 14, 383-392, 1975.

Twohy, C. H. and Rogers, D.: Air-flow and water-drop trajectories at instrument sampling points around the Beechcraft King Air and Lockheed Electra, J. Atmos. Ocean. Tech., 10, 566-578, 1993.

Yang, P., Baum, B. A., Heymsfield, A. J., Hu, Y.-X., Huang, H.-L., Tsay, S.-C., and Ackerman, S. A.: Single scattering properties of droxtals, J. Quant. Spectrosc. Ra., 79, 1159-1169, 2003.

Zhang, Z. B., Yang, P., Kattawar, G. W., Tsay, S.-C., Baum, B. A., Hu, Y. X., Heymsfield, A. J., and Reichardt, J.: Geometricaloptics solution to light scattering by droxtal ice crystals, Appl. Optics, 43, 2490-2499, 2004. 